\title{
Biological Synthesis of Polyketides from 6-n-Pentyl- $\alpha$-pyrone by Streptomyces sp.
}

\author{
Xifeng Li, Se-Kwon Kim, Jee H. Jung, ${ }^{\dagger}$ Jung Sook Kang, ${ }^{\dagger}$ Hong Dae Choi, ${ }^{\S}$ and Byeng Wha Son ${ }^{*}$
}

\author{
Department of Chemistry, Pukyong National University, Busan 608-737, Korea. E-mail: sonbw@pknu.ac.kr \\ ${ }^{\dagger}$ College of Pharmacy and ${ }^{\star}$ College of Dentistry, Pusan National University, Busan 609-735 and 602-739, Korea \\ ${ }^{\S}$ Department of Chemistry, Dongeui University, Busan 614-714, Korea
}

Received April 22, 2005

Key Words : Biological synthesis, 6- $n$-Pentyl- $\alpha$-pyrone, 6- $n$-(4-Oxopentyl)- $\alpha$-pyrone, 6- $n$-[(1S)-Hydroxypentyl]- $\alpha$-pyrone, Streptomyces sp.

Selectivity is an essential requirement in synthetic organic chemistry. The regioselectivity of enzymes even on complex or symmetric molecules without any need of protecting groups is a fundamental strength of biocatalysis. Biocatalysis are also a powerful tool for the regioselective and enantioselective synthesis of bioactive compounds, as well as for the generation of new, active, and less toxic derivatives for the bioactive natural products. ${ }^{1}$

The symmetric dipyrroloquinone, terreusinone, ${ }^{2}$ was regioselectively biotransformed to its unsymmetrical alcohol derivative, terreusinol, by the marine actinomycete Streptomyces sp. (MFAac18), ${ }^{3}$ which was isolated from a sample of sea plant Zostera marina collected at Bijin Island, Gyeongnam, using YPG (yeast, peptone, and glucose) agar medium.

In our continuing studies of the application of biocatalysis, ${ }^{3}$ we investigated the microbial transformation for 6- $n$-pentyl- $\alpha$-pyrone (1), which had been isolated as the antityrosinase active component from the marine isolate of the fungus Myrothecium sp. ${ }^{4}$

We wish to report the biological synthesis 6- $n$-(4-oxopentyl)- $\alpha$-pyrone (2) and 6- $n$-[(1S)-hydroxypentyl]- $\alpha$-pyrone (3) from 6- $n$-pentyl- $\alpha$-pyrone (1) by Streptomyces sp. (MFAac18).<smiles>CCCC[CH]c1cccc(=O)o1</smiles><smiles>CC(=O)CCCc1cccc(=O)o1</smiles>

2
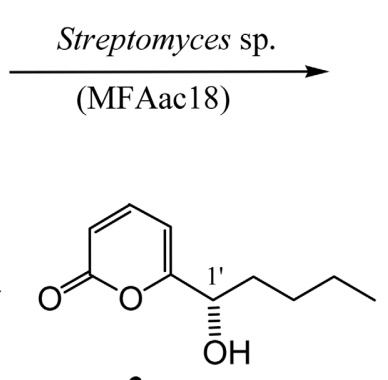

3
Biotransformation was carried out in the presence of a substance, 6- $n$-pentyl- $\alpha$-pyrone (1) (20 mg), by a two-stage fermentation protocol. ${ }^{3,5}$ The incubation was harvested after five weeks, and the filtered broth was extracted with EtOAc to afford a crude extract $(30 \mathrm{mg})$.

Chromatography of the extract $(30 \mathrm{mg}$ ) gave the biotransformed metabolites, 6- $n$-(4-oxopentyl)- $\alpha$-pyrone (2) (5 mg) and 6- $n$-[(1S)-hydroxypentyl]- $\alpha$-pyrone (3) $(3.5 \mathrm{mg})$.

6- $n$-(4-Oxopentyl)- $\alpha$-pyrone (2) was isolated as a colorless oil. A molecular formula of $\mathrm{C}_{10} \mathrm{H}_{12} \mathrm{O}_{3}$, which gave five degrees of unsaturation, was established by HR-EI-MS and ${ }^{13} \mathrm{C}$ NMR methods. The IR absorption spectrum of $\mathbf{2}$ showed bands characteristic of a $\alpha$-pyrone $\left(1728,1634,1559 \mathrm{~cm}^{-1}\right)$ and aliphatic ketone $\left(1720 \mathrm{~cm}^{-1}\right)$ functionality.

The overall NMR data indicated the presence of an $\alpha$ pyrone, which was further supported by UV spectral data [299 $\mathrm{nm}(\log \varepsilon 3.8)]$, and a pentanone.

On the basis of 2D NMR, COSY, HMQC, and HMBC correlations, the structure of 2 was proposed as the 6- $n$-(4oxopentyl)- $\alpha$-pyrone, which had been isolated as the antifungal metabolite, viridepyronone, from Trichoderma viride. ${ }^{6}$ In addition, compound $\mathbf{2}$ is the first example, to the best of our knowledge, from the biological synthesis.

6- $n$-[1(S)-Hydroxypentyl]- $\alpha$-pyrone (3) was isolated as a colorless oil. A molecular formula of $\mathrm{C}_{10} \mathrm{H}_{14} \mathrm{O}_{3}$, which gave four degrees of unsaturation, was established by HR-EI-MS and ${ }^{13} \mathrm{C}$ NMR methods.

The ${ }^{1} \mathrm{H}$ and ${ }^{13} \mathrm{C}$ NMR spectra of $\mathbf{3}$ were closely similar to those of 2 except for an oxygenated aliphatic methine [ $\delta_{\mathrm{H}}$ $\left.4.41\left(1 \mathrm{H}, \mathrm{dd}, \mathrm{H}-1^{\prime}\right) ; \delta_{\mathrm{C}} 71.0\left(\mathrm{C}-1^{\prime}\right)\right]$ newly appeared instead of an aliphatic ketone $\left[\delta_{\mathrm{C}} 207.7\left(\mathrm{C}-4^{\prime}\right)\right]$.

On the basis of 2D NMR analysis of 3 in conjunction with the molecular formula, the plane structure of $\mathbf{3}$ was proposed as the known 6- $n$-(1-hydroxypentyl)- $\alpha$-pyrone, which has been biotransformed from the same substrate (1). ${ }^{7}$

The unsolved stereochemistry of $\mathbf{3}$ led us to do further structural examination of this compound. The advanced Mosher's method ${ }^{8}$ was applied to determine absolute configuration. Esterification of $\mathbf{3}$ with $(R)-(-)-$ and $(S)-(+)-\alpha-$ methoxy- $\alpha$-trifluoromethylphenylacetyl chloride (MTPACl) by 1,3-dicyclohexylcarbodiimide (DCC) and 4-(dimethylamino)pyridine (DMAP) in $\mathrm{CH}_{2} \mathrm{Cl}_{2}$ yielded $(S)$-MTPA ester (3a) and $(R)$-MTPA ester (3b), respectively. The assignments of 3a and $\mathbf{3 b}$ were achieved by ${ }^{1} \mathrm{H}$ NMR, and the chemical shift differences between $\mathbf{3 a}$ and $\mathbf{3 b}$ (Figure 1) indicated an $S$ configuration at C-1'. Thus, the stereostructure of $\mathbf{3}$ was established as 6- $n$-[1(S)-hydroxypentyl]- $\alpha$-pyrone (3).

Compounds 1 exhibited a tyrosinase inhibitory activity ${ }^{9}$ with $\mathrm{ED}_{50}$ value of $0.8 \mu \mathrm{M}$, which are more active than kojic acid $\left(\mathrm{ED}_{50}, 7.7 \mu \mathrm{M}\right)$. However, the biotransformed metabolites $(\mathbf{2}, \mathbf{3})$ were inactive in tyrosinase inhibitory assay. Thus, the size and functional group of $n$-pentyl side chain in $\mathbf{1}$ were supposed to be important for displaying the antityrosinase activity. 


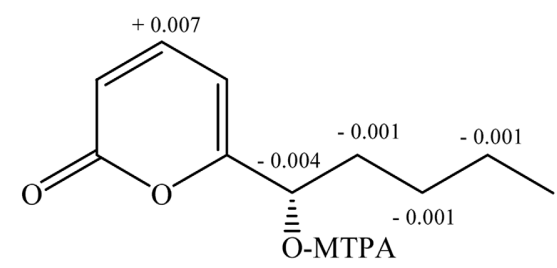

3a: $(S)$-MTPA ester

3b: $(R)$-MTPA ester

Figure 1. $\Delta \delta$ values $\left(\delta_{S}-\delta_{R}\right)$ for $(S)$ - and (R)-MTPA esters of compound $\mathbf{3}$.

\section{Experimental Section}

General. Optical rotation was determined on a Perkin Elmer model 341 polarimeter. IR spectrum was recorded on a Bruker FT-IR model IFS-88 spectrometer. ${ }^{1} \mathrm{H}(400 \mathrm{MHz})$ and ${ }^{13} \mathrm{C}$ NMR (100 MHz) spectra were obtained on a JEOL JNM-ECP 400 NMR spectrometer, using TMS or solvent peaks as reference standard. MS spectra were obtained on a JEOL JMS-700 spectrometer. UV/visible spectra were measured on a Hitachi U-2001 UV/Vis spectrometer.

Isolation of the bacterium Streptomyces species. The actinomycete species, isolate MFAac18, was isolated using YPG agar medium, composed of $0.5 \%$ yeast extract, $0.5 \%$ peptone, $1.0 \%$ glucose, $1.6 \%$ agar, $40 \%$ deionized water, and $60 \%$ seawater, containing penicillin and streptomycin (each $250 \mu \mathrm{g} / \mathrm{mL}$ ), from the sea plant Zostera marina collected at the Bijin Island, Tongnyeong, Gyeongnam Province, Korea in 2000. The culture showed ash gray vegetative mycelia and demonstrated fatty acid composition (Korean Culture Center of Microorganisms, Seoul, Korea) and growth characteristics typical of actinomycete belong to the Streptomyces and related genera.

Biotransformatin of 1. A two-stage fermentation protocol $^{5}$ was used for preparative scale formation of the metabolite of 1 . The SWS medium contained soytone $(0.1 \%)$, soluble starch $(1.0 \%)$, and seawater $(100 \%)$, and it was autoclaved at $121{ }^{\circ} \mathrm{C}$ for $15 \mathrm{~min}$. Preparative incubation was conducted in $1 \mathrm{~L}$ of sterile medium held in $3 \mathrm{~L}$ culture flask that was incubated at $29^{\circ} \mathrm{C}$ for 1 week (static). A $10 \%$ inoculum derived from one week old stage I culture was used to initiate stage II culture, which was incubated for $24 \mathrm{~h}$ more before receiving $20 \mathrm{mg}$ of 1 in $0.75 \mathrm{~mL}$ of $N, N$ dimethyl formamide (DMF), and incubation was continued at $29{ }^{\circ} \mathrm{C}$ for five weeks (static). Substrate control consisted of sterile medium and substrate incubated under the same conditions but without microorganism. Also, culture control was composed of fermentation blanks in which the microorganism was grown under identical condition but without the addition of substrate. After five weeks of incubation, each control was harvested and analyzed by TLC. The culture was filtered through cheesecloth, and the filtrate was extracted with EtOAc. The organic layer was dried over anhydrous $\mathrm{Na}_{2} \mathrm{SO}_{4}$, filtered through sintered glass, and vacuum-concentrated to yield a crude extract $(30 \mathrm{mg})$.

Isolation of the biotransformed metabolites ( 2 and 3 ).
The crude extract $(30 \mathrm{mg})$ was subjected to silica gel flash column chromatography using in sequence $n$-hexane-EtOAc (100:0-0:100) to give two fractions $\mathrm{A}$ and $\mathrm{B}$, which contained substrate $(\mathbf{1})$ and metabolites $(\mathbf{2}, \mathbf{3})$, respectively. Fractions A and B were separately purified by reversedphase ODS-A gel (YMC Co.) flash column chromatography using $\mathrm{MeOH}$, followed by HPLC (ODS-A, MeOH) to furnish the substrate (1) (9 mg) and the metabolites, 2 (5 mg) and $3(3.5 \mathrm{mg})$, respectively.

6- $n$-(4-Oxopentyl)- $\alpha$-pyrone (2) and 6- $n$-[(1S)-hydroxypentyl]- $\alpha$-pyrone (3) were isolated as a colorless oil which showed spectral data virtually identical to those reported in the literatures, respectively. ${ }^{6,7}$ The rotation recorded for $\mathbf{3}$ isolated in this study was $[\alpha]_{\mathrm{D}}+15^{\circ}\left(c 0.7, \mathrm{CHCl}_{3}\right)$.

Preparation of MTPA esters (3a, 3b). To a $\mathrm{CH}_{2} \mathrm{Cl}_{2}$ solution $(50 \mu \mathrm{L})$ of $\mathbf{3}(0.5 \mathrm{mg})$, 4-DMAP $(50 \mu \mathrm{g})$, and DCC $(50 \mu \mathrm{g})$ was added $(R)-(-)-\operatorname{MTPACl}(5 \mu \mathrm{L})$ and $(S)-(+)-$ MTPACl $(5 \mu \mathrm{L})$ at r.t., respectively. Each mixture was stirred for $24 \mathrm{hr}$ and 3-[(dimethylamino)propyl] amine $(3 \mu \mathrm{L})$ was added. After standing for $10 \mathrm{~min}$, the solvent was evaporated. The residues were purified by preparative TLC ( $n$-hexane-EtOAc, $2: 1)$ to give $(S)$-MTPA ester (3a) $(0.3$ $\mathrm{mg}$ ) and $(R)$-MTPA ester (3b) $(0.3 \mathrm{mg})$, respectively.

$(S)$-MTPA ester (3a): ${ }^{1} \mathrm{H}$ NMR $\left(\mathrm{CDCl}_{3}, 400 \mathrm{MHz}\right) \delta 6.168$ $(1 \mathrm{H}, \mathrm{d}, J=9.4 \mathrm{~Hz}, \mathrm{H}-3), 7.299(1 \mathrm{H}, \mathrm{dd}, J=9.4,6.4 \mathrm{~Hz}, \mathrm{H}-$ 4), $6.168(1 \mathrm{H}, \mathrm{d}, J=6.4 \mathrm{~Hz}, \mathrm{H}-5), 4.122(1 \mathrm{H}, \mathrm{dd}, J=7.3,5.1$ Hz, H-1'), 1.685 (1H, m, H-2'), 1.417 (1H, m, H-2'), 1.313 (4H, m, H $\left.2_{2}-3^{\prime} / 4^{\prime}\right), 0.902\left(3 \mathrm{H}, \mathrm{t}, J=7.3 \mathrm{~Hz}, \mathrm{H}_{3}-5^{\prime}\right), 3.492(3 \mathrm{H}$, s, OMe), 7.529 (3H, m, Ph), $7.706(2 \mathrm{H}, \mathrm{m}, \mathrm{Ph})$.

(R)-MTPA ester (3b): ${ }^{1} \mathrm{H}$ NMR $\left(\mathrm{CDCl}_{3}, 400 \mathrm{MHz}\right) \delta$ $6.168(1 \mathrm{H}, \mathrm{d}, J=9.4 \mathrm{~Hz}, \mathrm{H}-3), 7.292(1 \mathrm{H}, \mathrm{dd}, J=9.4,6.4$ Hz, H-4), 6.168 (1H, d, $J=6.4$ Hz, H-5), 4.126 (1H, dd, $J=$ 7.3, 5.1 Hz, H-1'), 1.685 (1H, m, H-2'), 1.418 (1H, m, H-2'), $1.314\left(4 \mathrm{H}, \mathrm{m}, \mathrm{H}_{2}-3^{\prime} / 4^{\prime}\right), 0.902$ (3H, t, $\left.J=7.3 \mathrm{~Hz}, \mathrm{H}_{3}-5^{\prime}\right)$, 3.492 ( $3 \mathrm{H}, \mathrm{s}, \mathrm{OMe}), 7.529$ (3H, m, Ph), 7.706 (2H, m, Ph).

Acknowledgment. X. L. acknowledges the support of the Brain Korea 21 (BK21) (F020). Mass spectral data were kindly provided by the Korea Basic Science Institute. This work was supported by grant No. (R01-2004-000-10467-0) from the Basic Research Program of the Korea Science \& Engineering Foundation.

\section{References}

1. Rasor, J. P.; Voss, E. Applied Catalysis A: General 2001, 221, 145-158.

2. Lee, S. M.; Lee, X. F.; Jiang, H.; Cheng, J.; Seong, S.; Choi, H. D.; Son, B. W. Tetrahedron Lett. 2003, 44, 7707-7710.

3. Li, X.; Lee, S. M.; Choi, H. D.; Kang, J. S.; Son, B. W. Chem. Pharm. Bull. 2003, 51, 1458-1459.

4. Li, X.; Kim, M. K.; Lee, U.; Kim, S.-K.; Kang, J. S.; Choi, H. D.; Son, B. W. Chem. Pharm. Bull. 2005, 53, 453-455.

5. Smith, R. V.; Rosazza, J. P. J. Pharm. Sci. 1975, 64, 1737-1759.

6. Evidente, A.; Cabras, A.; Maddau, L.; Serra, S.; Andolfi, A.; Motta, A. J. Agric. Food Chem. 2003, 51, 6957-6960.

7. Cooney, J. M.; Lauren, D. R. J. Nat. Prod. 1999, 62, 681-683.

8. Ohtani, I.; Kusumi, T.; Kashman, Y.; Kakisawa, H. J. Am. Chem. Soc. 1991, 113, 4092-4096.

9. Li, X.; Li, Y.; Jeong, J. H.; Lee, K. T.; Choi, H. D.; Son, B. W. Kor. J. Pharmacogn. 2003, 34, 138-141. 